\title{
Placas para alvenaria de vedação com uso de espuma de poliestireno expandido (EPS)
}

\author{
Sealing masonry units with expanded polystyrene foam (EPS) \\ Leandro Moreno De Souza', Cleber Decarli de Assis²
}

\begin{abstract}
'Acadêmico do Curso de Engenharia Civil, Instituto Tocantinense Presidente Antônio Carlos, Porto Nacional -TO , Brasil
${ }^{2}$ Professor do Curso de Engenharia Civil, Instituto Tocantinense Presidente Antônio Carlos, Porto Nacional -TO, Brasil
\end{abstract}

\begin{abstract}
Resumo
O poliestireno expandido é um material 100\% reciclável, tal forma contribui com a diminuição dos impactos ambientais, essa contribuição ocorre evitando o mau uso dos resíduos, que atualmente são depositados em aterros sanitários ou lixões sem nenhum controle, causado, devido ao grande volume ocupado e à dificuldade de evitar que se espalhem por ação eólica, danos ao meio ambiente. Outro aspecto é o gasto com energia associado ao processo de fabricação de poliestireno expandido (Isopor): no caso da reciclagem, pode-se permitir redução de insumo (eletricidade, combustível etc.), já que várias etapas iniciais da fabricação da matéria-prima virgem podem ser eliminadas. Deve-se considerar que o poliestireno expandido é obtido do petróleo, que é um recurso mineral natural esgotável, e sua reciclagem implica uma melhor utilização desse insumo energético. a espuma de poliestireno expandido apresenta inúmeras vantagens não só em relação a questão ambiental, como também: baixa condutividade térmica, massa específica reduzida que varia entre 10 e $30 \mathrm{Kg} . \mathrm{m}^{3}$, baixa absorção de água, baixo peso, facilidade de manuseio, versatilidade, resistência ao envelhecimento, absorção de choques. Tais características levam a observar que se trata de um material inovador, para o qual vêm sendo descobertos e desenvolvidos usos cada vez mais nobres e cujas possibilidades de aplicação ainda parecem longe de estarem totalmente aproveitadas, mesmo depois de mais de meio século de aplicação.
\end{abstract}

Palavras-chave: Sustentável. Isopor. Resistência.

\begin{abstract}
Expanded polystyrene is a $100 \%$ recyclable material, such contributes to the reduction of environmental impacts, this contribution occurs preventing the misuse of wastes that are currently disposed of in landfills or dumps with no control, caused due to the large volume occupied and the difficulty of preventing spread by wind action, damage to the environment. Another aspect is the power consumption associated with the manufacturing process of expanded polystyrene ( Styrofoam ) in the case of recycling, it may be possible to reduce the input (electricity , fuel, etc.). Since several initial manufacturing steps of the raw material virgin can be eliminated. One must consider that the expanded polystyrene is obtained from petroleum, which is an exhaustible natural mineral resource, and recycling means better use of this energy source . Expanded polystyrene foam has many advantages not only in relation to environmental issues, as well : low thermal conductivity, low density, which varies between 10 and $30 \mathrm{~kg} \cdot \mathrm{m}^{-}{ }^{3}$, low water absorption, low weight, ease of handling, versatility, aging resistance, shock absorption. These characteristics lead to note that this is an innovative material for which have been discovered and developed more and more noble uses and whose application possibilities still seem far from being fully exploited, even after more than half a century of application.
\end{abstract}

Keywords: Styrofoam. Resistance. Sustainability. 


\section{GENERALIDADES}

Segundo Leite (2001) a reciclagem de resíduos sólidos provenientes da atividade da construção civil tem se mostrado uma boa alternativa de redução de impactos ambientais diminuindo a extração desordenada de matéria prima do meio natural e contribuindo também com a diminuição de áreas de disposição (aterros sanitários, lixões) ocasionado pelo grande volume de resíduos dercatados a cada ano em todo mundo. Desta forma pode ser reaproveitado de forma sustentável dentro do próprio setor da construção civil isso é um grande desafio para o meio técnico - científico, no sentido de inovar esse quadro.

De acordo com Silva (2010) a prática da construção civil é um dos principais geradores de resíduos sólidos, sendo em grande quantidade e diversificada, isso se dá devido à falta de conscientização ambiental assim como a falta de planejamento e a mão de obra não qualificada, contribuindo para o acréscimo dos problemas ambientais.

Segundo Tessari (2006), para alcançar um estágio de sustentabilidade é fundamental uma mudança de postura por parte da sociedade com ênfase para os atores envolvidos na cadeia produtiva da construção civil, com a adoção de ações efetivas que possibilitem a eles aprender a avaliar seu bem-estar e as condições ambientais, implementar medidas corretivas a curto prazo com o objetivo de reduzir os danos ambientais e também, o uso dos recursos naturais não renováveis, priorizando a eficiência e a reciclagem.

O estudo acrescenta que o padrão de geração de lixo no País já equivale à média dos países europeus - tendência que havia sido verificada no estudo anterior, de 2009. O brasileiro, em média, produz 1,213 kg de resíduos por dia. Na Região Sudeste, o montante chega a 1,298 kg por habitante/ dia. O europeu produz, em média, $1,2 \mathrm{~kg}$ por dia, e o americano, 2,8 kg. (ESTADÃO, 2011).

Os resíduos sólidos da construção civil quando reciclados podem ser aproveitados da várias maneiras. Quando se faz um processo de classificação e moagem dos resíduos sólidos, obtém-se agregados para diversas finalidades, tais como: base para pavimentação, contenção de encostas, blocos de concretos, tubos para drenagem etc. Podemos com custos competitivos obter produtos similares e com ótimo desempenho (SILVA, 2010).

Em relação à construção civil, o aproveitamento de resíduos é uma das ações que devem ser incluídas nas práticas comuns de produção de edificações, visando a sua maior sustentabilidade, proporcionando economia de recursos naturais e minimização do impacto no meio - ambiente (SILVA, 2010).

O potencial do reaproveitamento e reciclagem de resíduos da construção é enorme, a incorporação destes resíduos em determinados produtos pode vir a ser extremamente benéfica, já que proporciona economia de matéria-prima e energia (BARROS, 2010).

\section{CLASSIFICAÇÃO DOS RESÍDUOS}

Segundo Silva (2010) os resíduos sólidos decorrentes de demolição e da construção civil são responsáveis por um grande impacto ambiental, são dispostas de maneira clandestina, em terreno baldio, áreas públicas, ou em aterros.

Esta prática tem diminuído, devido ao avanço nas políticas de gerenciamento de resíduos sólidos com a criação da Resolução n ${ }^{\circ} 307$ do Conselho Nacional do Meio Ambiente (CONAMA, 2002), que estabelece diretrizes, critérios e procedimentos para a gestão destes resíduos, classificando-os em quatro diferentes classes:

- Classe A - Resíduos reutilizáveis ou recicláveis como agregados (tijolos, concreto etc.)

- Classe B - Resíduos reutilizáveis / recicláveis industriais (plásticos, papel, etc.)

- Classe C - Resíduos para os quais não foram desenvolvidas tecnologias viáveis que permitam sua reciclagem (gesso e outros)

- Classe D - Resíduos perigosos (tinta, solvente, etc.) ou contaminados (de clínicas radiológicas, instalações industriais e outros.

As classificações de gerenciamento de resíduos sólidos estão divididas em 2 grupos segundo a NBR 10004. Sendo os de classe I perigosos e classe II não perigosos. Os não perigosos 


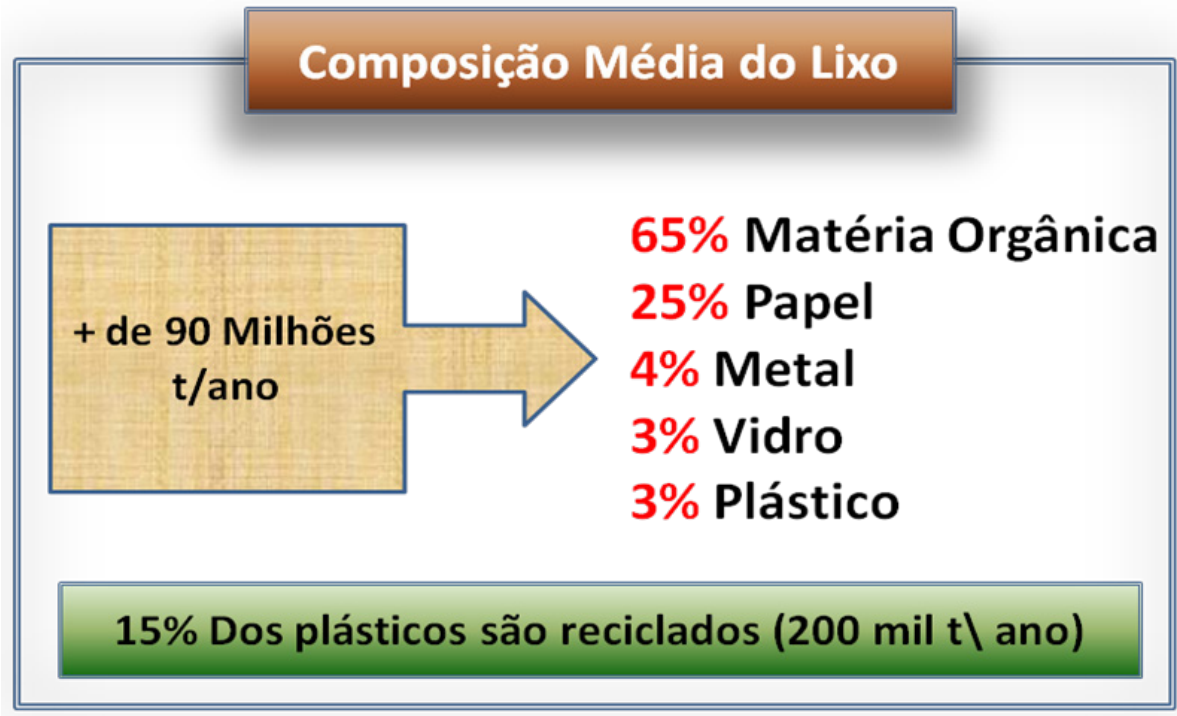

Figura 1 - Composição do lixo no Brasil Fonte: Abrapex

Tabela 1 - Classificação dos resíduos sólidos.

\begin{tabular}{|c|c|c|}
\hline Classe dos Resíduos & Estado & Descrição \\
\hline Classe I & Perigoso & $\begin{array}{l}\text { Resíduos que apresentam periculosidade } \\
\text { (apresentam riscos à saúde pública e riscos ao } \\
\text { meio ambiente), inflamabilidade (caracterizado } \\
\text { como inflamável), corrosividade (qualificado como } \\
\text { corrosivo), reatividade (resíduo reativo), toxicidade } \\
\text { (resíduos caracterizado tóxico) e patogenicidade } \\
\text { (caracterizado como patogênico); }\end{array}$ \\
\hline Classe II A & Não Inertes & $\begin{array}{l}\text { Resíduos que não se se enquadram na Classe I - } \\
\text { Perigosos ou Resíduo classe II B - Inertes. Nestes } \\
\text { é possível ter propriedade como } \\
\text { biodegradabilidade, combustibilidade } \\
\text { solubilidade em água; }\end{array}$ \\
\hline Classe II B & Inertes & $\begin{array}{l}\text { Resíduos que não tiveram seus constituintes } \\
\text { solubilizados a concentrações superiores aos } \\
\text { padrões de potabilidade de água, excetuando-se a } \\
\text { aspectos, sabor, dureza, cor e turbidez. }\end{array}$ \\
\hline
\end{tabular}

Fonte: NBR 10004

(classe II) são subdividida em não inertes (Classe II A) e inertes (Classe II B). A tabela 1 mostra a classificação dos resíduos sólidos de acordo com a NBR 10004. 

a tabela 2 .

Segundo Kraemer (2005) pode-se subdividir os resíduos quanto a sua origem conforme mostra

Tabela 2 - Classificação de resíduos sólidos quanto a sua origem

\begin{tabular}{l|c|c}
\hline \hline \multicolumn{1}{c|}{ Origem } & 2 & Responsável \\
\hline \hline Domiciliar & 2,3 & Prefeitura \\
\hline Comercial & $1,2,3$ & Prefeitura \\
\hline Industrial & 2,3 & Gerador do resíduo \\
\hline Público & $1,2,3$ & Gerador do resíduo \\
\hline Serviços de saúde & $1,2,3$ & Gerador do resíduo \\
\hline $\begin{array}{l}\text { Portos, aeroportos e terminais } \\
\text { ferroviários. }\end{array}$ & $1,2,3$ & Gerador do resíduo \\
\hline Agrícola & 3 & Gerador do resíduo \\
\hline Entulho & & \\
\hline \hline
\end{tabular}

Fonte - Kraemer, (2005)

\section{ESPUMA DE POLIESTIRENO EXPANDIDO}

Na América Latina, a aplicação das espumas flexível de poliuretano em colchões e estofada é da ordem de $57 \%$ da demanda total, enquanto que as aplicações automotivas respondem por $10 \%$. As espumas rígidas mobilizam uma parcela aproximada de $16 \%$ e são usadas principalmente em isolamento térmico e construção civil. Os segmentos de poliuretano sólidos, como os adesivos e selantes, elastômeros, solados, tintas e revestimentos correspondem a 17\% do consumo desse material (VILAR, 2007).

Segundo a Abrapex (2011), estima-se que anualmente são consumidos no mundo uma quantia de 2,5 milhões de toneladas de EPS, deste montante o Brasil consome aproximadamente 40 mil toneladas por ano de EPS, sendo que deste total utilizados ficam subdivididos em $45 \%$ foram destinados à construção civil nas diversas formas de uso do material, outra parte chegando a $42 \%$ destinada a embalagens industriais, e cerca de $13 \%$ destinado a artigos de consumo, e dados do Brasil também comprovam que desse total utilizado 15 mil toneladas, o que equivalem $37,5 \%$ do total utilizado tem como destino o lixo.

A espuma de poliestireno expandido é um material considerado ecologicamente correto, pois o mesmo não contamina o solo, a água e o ar, além do mais pode ser reciclável e reaproveitado, voltando à condição de matéria prima.

Segundo a Acepe (2011), são diversas as formas que podemos utilizar o EPS na construção civil isso se da de acordo com suas inúmeras vantagens citadas a seguir.

- Baixa condutibilidade térmica: A estrutura de células fechadas, cheias de ar, dificultam a passagem do calor o que confere ao EPS um grande poder isolante.

- Leve: As densidades do EPS variam entre os 10-30 kg/m3, permitindo uma redução substancial do peso das construções.

- Resistência mecânica: Apesar de muito leve, o EPS tem uma resistência mecânica elevada, que permite o seu emprego onde esta característica é necessária, trata-se de um material que pesa entre 13 a $25 \mathrm{~kg} / \mathrm{m}^{3}$, e apresenta características de resistência à compressão de 1 a $2 \mathrm{~kg} / \mathrm{cm} 2$.

- Baixa absorção de água e insensível à umidade: O EPS não é higroscópio. Mesmo quando 
imerso em água o EPS absorve apenas pequenas quantidades de água. Tal garante que o EPS mantém as suas características térmicas e mecânicas mesmo sob a ação da umidade.

- Fácil de manusear: O EPS é um material que se trabalha com as ferramentas habitualmente disponíveis, garantindo a sua adaptação perfeita à obra. O baixo peso do EPS facilita o manuseamento do mesmo em obra. Todas as operações de movimentação e colocação resultam significativamente encurtadas.

- Resistente quimicamente: O EPS é compatível com a maioria dos materiais correntemente utilizados na construção de edifícios, tais como cimento, gesso, cal, água, etc.

- Versátil: O EPS pode apresentar-se de tamanhos e formas, que se ajustam sempre às necessidades específicas da construção.

- Resistente ao envelhecimento: Todas as propriedades do EPS mantêm-se inalteradas ao longo da vida do material, que é pelo menos tão longa quanto a vida da construção de que faz parte. O EPS não apodrece nem ganha bolor, não é solúvel em água nem liberta substancias para o ambiente. O EPS não constitui substrato ou alimento para o desenvolvimento de animais ou microrganismos.

são:

De acordo com a Diiso (2011) as principais características da espuma de poliestireno expandido

- Baixo peso específico;

- Alta resistência à compressão;

- Elasticidade;

- Baixa condutibilidade térmica;

- Estabilidade térmica;

- Nenhuma ascensão capilar;

- Baixa absorção de água e umidade;

- Inodoro;

- Não embolora;

- Adere a outros plásticos;

- Isolamento Acústico;

- Durabilidade

\section{APLICAÇÃO DA ESPUMA DE POLIESTIRENO EXPANDIDO}

Para quem tem fácil acesso ao reaproveitamento do EPS, o concreto leve, além de versátil, é vantajoso economicamente. Pelo seu coeficiente de dilatação menor que concretos convencionais, prefeituras que contam com coleta seletiva de lixo podem utilizar o EPS moído na produção de concreto leve para calçadas, quadras esportivas, bancos de jardim, vasos, balaústres, casas pré-fabricadas, enfim, quase tudo que se faz com concreto à exceção de estruturas (ABRAPEX, 2011).

Segundo a Abrapex (2011) a espuma de poliestireno expandido tem varias finalidades na construção civil como podemos ver listados a seguir:

- Enchimento de Lajes e Fôrmas para Concreto

- Lajes Industrializadas

- Isolamento Térmico de Lajes Industrializadas

- Isolamento Térmico de Telhados

- Isolamento Térmico de Dutos de Ar Condicionado

- Isolamento Térmico de Tubulações e Reservatóriosw

- Isolamento Térmico de Câmaras Frigoríficas

\section{APLICAÇÃO DO CONCRETO LEVE COM EPS}

Segue abaixo algumas possíveis aplicações do uso do concreto leve na construção civil de acordo com a (ABRAPEX, 2011):

- Regularização de lajes em geral: Inclinação para escoamento

- Painéis de fechamento: Prédios/casas pré-fabricadas/galpões. 
- Elementos pré-fabricados: Lajotas/blocos vazados, pilares para muros, elementos vazados, elementos decorativos para fachadas e jardins

- Pavimentos: Calçadas, painéis para fechamento de galerias

- Elementos tipo "móveis": Bancos para ambientes externos, base para montagem de sofás / balcões / camas.

- Áreas de Lazer: Quadras de esporte, base para dispositivos de exercícios.

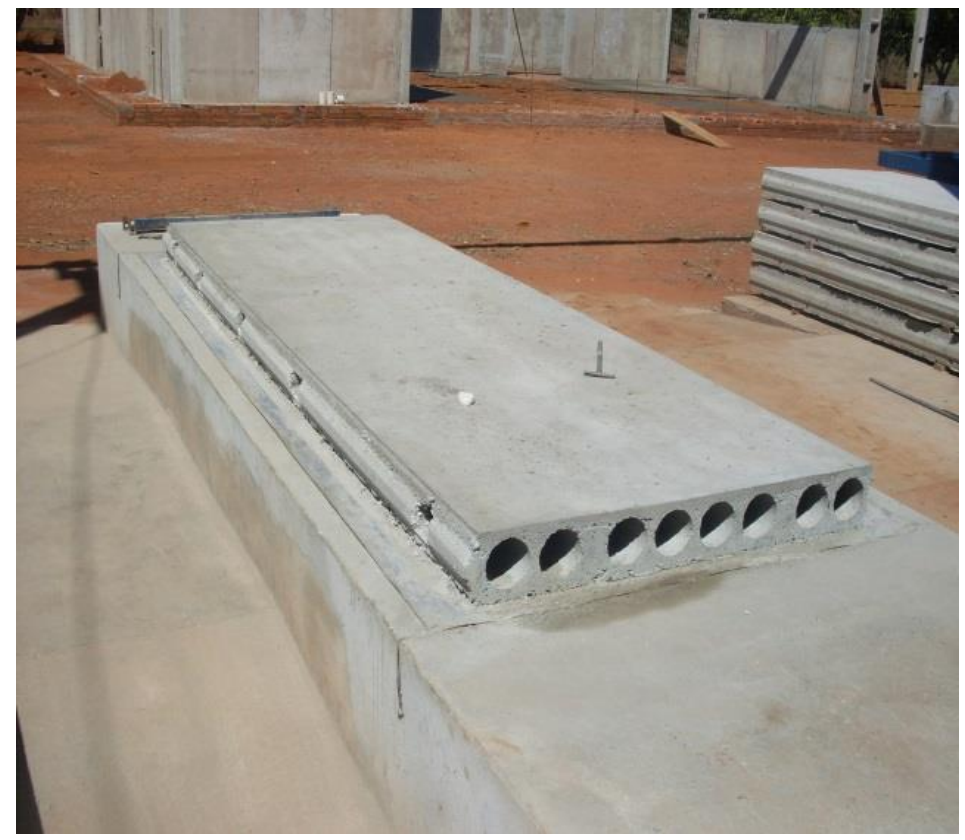

Figura 2 - Placa modular de concreto leve Fonte: Autor (2014)

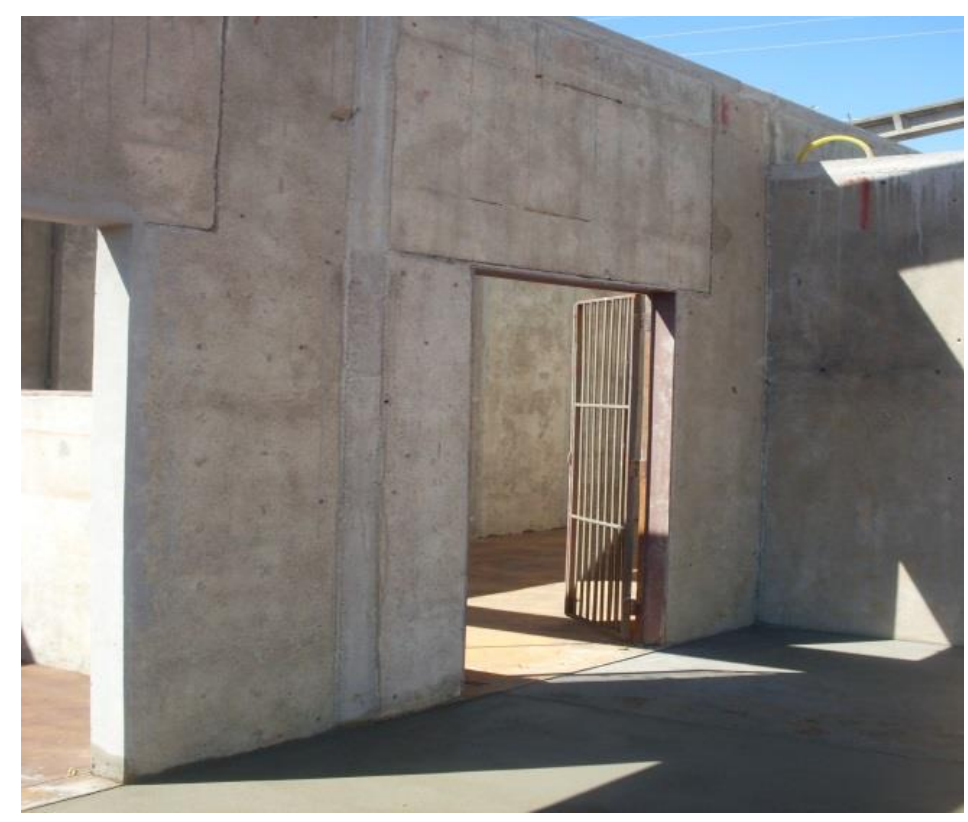

Figura 3- Modulação das Placas

Fonte: Autor (2014) 


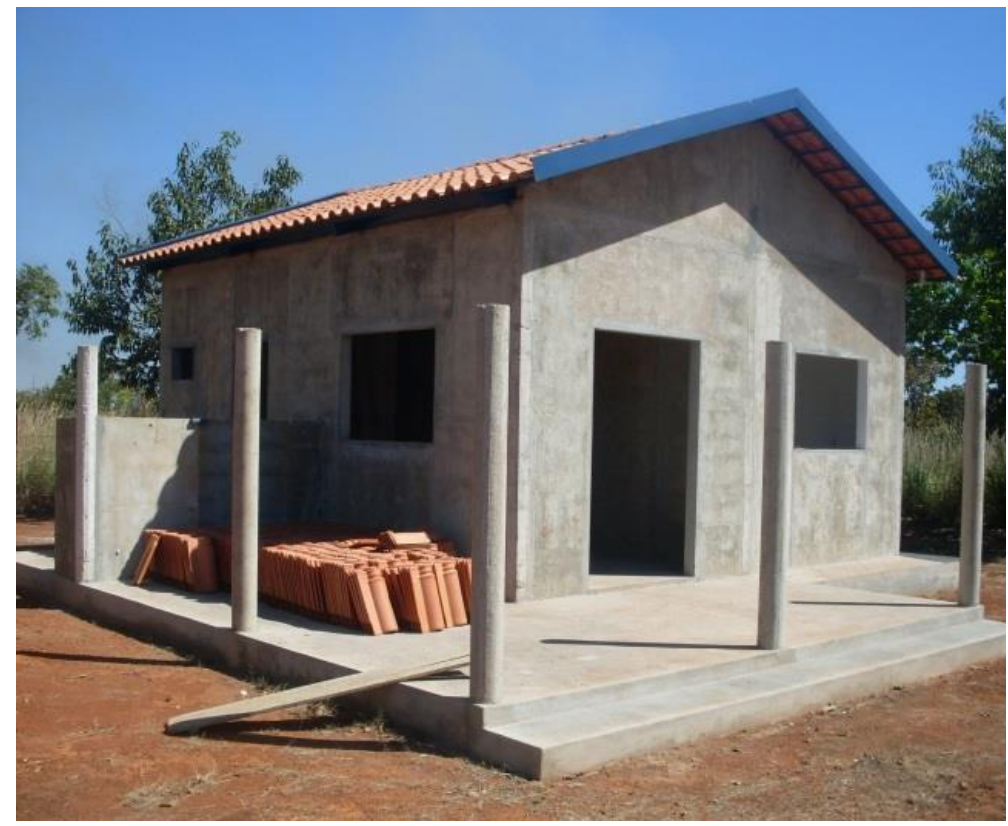

Figura 4 - Casa pré-moldada no acabamento

Fonte: Autor (2014)

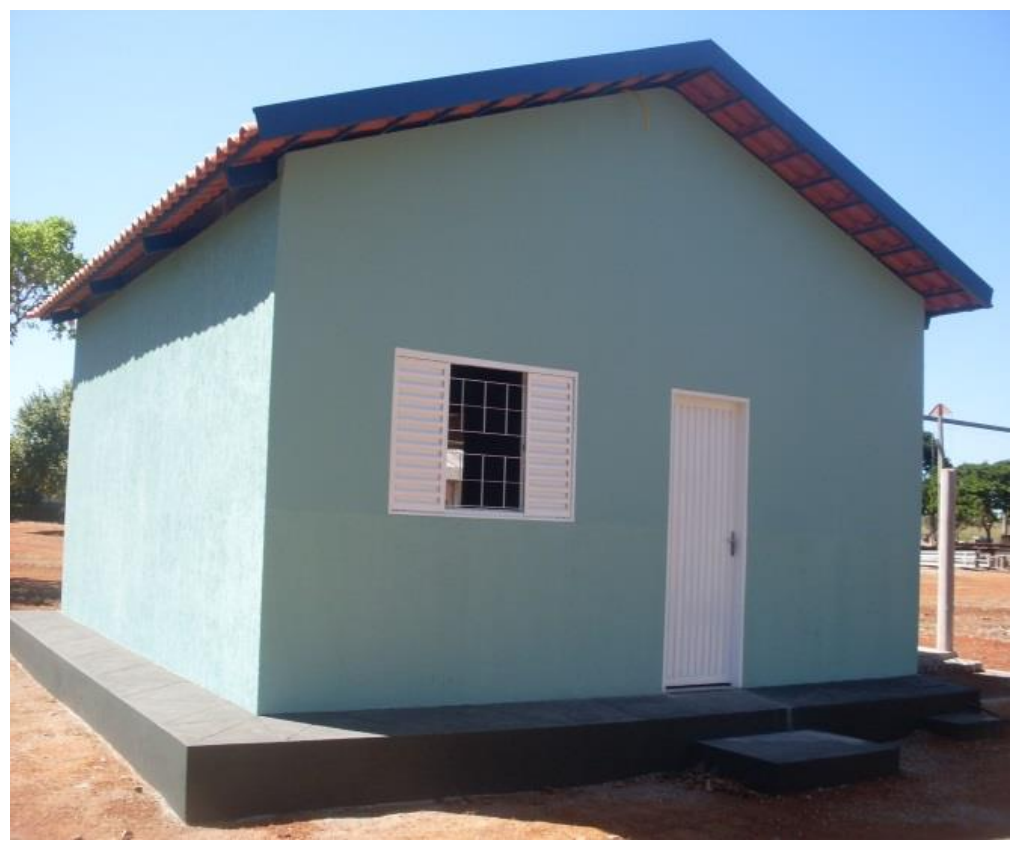

Figura 5 - Facilidade no acabamento

Fonte: Autor (2014)

\section{CONSIDERAÇÕES FINAIS}

O concreto leve tem uma característica de extrema relevância que é a característica de isolamento térmico e acústico e aliado a isso o baixo custo em relação aos convencionais e torna-se uma boa opção para ser utilizado como vedação de paredes. Com base nessa informação e proposto o uso do concreto leve na vedação de residências na fabricação de blocos de concreto leve ou placas modelares pré-fabricas, conforme citado na revisão o material possibilita um ambiente com um desempenho térmico e acústico elevado e faz-se exigências dessas características atualmente na NBR 15575/08.

O uso de bloco de concreto associado ao poliestireno expandido é bastante promissor, principalmente por possuir característica isolante, e de certa forma trata-se de um sistema construtivo sustentável, 
o mesmo em pesquisa concluiu que ficou evidente que o resíduo de EPS é um isolante térmico eficiente tanto do ponto de vista técnico como ambiental (menor consumo de energia e redução de resíduos), seria uma alternativa para, a melhoria do conforto dos ambientes construídos.

Conclui-se que é uma boa alternativa, pois O EPS e um plástico celular rígido, resultante da polimerização do estireno em água. Em seu processo produtivo não se utiliza e nunca se utilizou o gás clorofluorcarbono (CFC) ou qualquer um de seus substitutos. Como agente expansor para a transformação do EPS, emprega se o Pentano, um hidrocarboneto que se deteriora rapidamente pela reação fotoquímica gerada pelos raios solares, sem comprometer o meio ambiente.

No que diz respeita a diminuição da massa específica do concreto, ou seja, o seu peso ao ocupar um certo volume o mesmo acaba apresentando valores inferiores aos convencionais, o uso de EPS ainda apresenta um material com apropriada resistência, além de tratar de um material com bom performance térmico, acústico e de tecnologia viável no aspecto ambiental, diminuindo os impactos causados pela disposição final do poliestireno expandido em aterros sanitários, pois é de conhecimento que o mesmo é um material que já vem sendo empregado em vários aspectos na construção civil como em outras áreas, mas o propósito é a reciclagem dos materiais provenientes de refugo.

\section{REFERÊNCIAS}

ABRAPEX Associação Brasileira de Poliestireno Expandido. Disponível em <www.abrapex.com.br>. Acesso em abril de 2011.

ACEPE - Associação Industrial de Poliestireno Expandido. Disponível em <www.acepe.pt/eps/eps_qeps.asp> Acesso em abril de 2011.

CONSELHO NACIONAL DO MEIO AMBIENTE. Dá diretrizes gerais para uso e implementação da Avaliação de Impacto Ambiental. Resolução CONAMA n 001. Brasília, 1986. Dispõe sobre gestão dos resíduos da construção civil. Resolução CONAMA n 307. Brasília, 2002.

DIISO. Indústria de EPS. Sobre o EPS. Disponível em: http://www.diiso.com.br/default.asp?Conteudo=EPS. Acesso em abril de 2011.

ESTADÃO em: http://estadao.br.msn.com/ciencia/artigo.aspx?cp-documentid=28504344 acesso em: abril de 2011.

KRAEMER, Maria Elisabeth Pereira. A questão ambiental e os resíduos industriais. Disponível em: <http:// www.gestaoambiental.com.br/articles.php?id=65 > . Acesso em abril de 2011.

LEITE, M. B. Avaliação De Propriedades Mecânicas De Concretos Produzidos Com Agregados Reciclados De Resíduos De Construção E Demolição. Porto Alegre. Tese De Doutorado Em Engenharia Civil, Programa De Pós Graduação Em Engenharia Civil, Universidade Federal Do Rio Grande Do Sul, 2001.

NBR 10004 - Resíduos Sólidos. Rio de Janeiro, 2004.

NBR 15575- Norma De Desempenho. Rio de Janeiro, 2008.

PINHEIRO, Libânio M.; MUZARDO. Cassiane D.;SANTOS Sandro P. Estruturas de concreto - Capitulo 1. São Paulo. 2004.

SILVA L. R. A. D. Utilização Do Entulho Como Agregado Para A Produção De Concreto Reciclado. Dissertação apresentada ao Programa de Pós-Graduação em Engenharia Civil da Universidade Federal Fluminense, como requisito parcial para obtenção do Grau de Mestre. Área de Concentração: Engenharia Civil (2010).

TESSARI, Janaina. Utilização de Poliestireno Expandido e Potencial de Aproveitamento de seus Resíduos 
pela Construção Civil. 2006. 102f. Dissertação (Mestrado em Engenharia Civil) - Universidade Federal de Santa Catarina, Florianópolis.

VILAR, WALTER DIAS. Químicas e Tecnologia dos Poliuretanos. 3. ed. São Paulo: Editora Pronor, 2007. 